\title{
Matéria
}

Revista Matéria, v. 15, n. 2, pp. 157-163, 2010.

ISSN 1517-7076

http://www.materia.coppe.ufrj.br/sarra/artigos/artigo11210

\section{Effects of temperature and strain rate on the tensile properties of twip steels}

\author{
S. Curtze; V.-T. Kuokkala \\ Department of Materials Science, Tampere University of Technology, P.O. Box 589, FI-33101 Tampere, \\ Finland. \\ e-mail: veli-tapani.kuokkala@tut.fi ; sven.curtze@tut.fi
}

\begin{abstract}
Three high manganese TWIP steels were produced with stacking fault energies $\gamma_{S F E}$ ranging from 20.5 to $42 \mathrm{~mJ} / \mathrm{m}^{2}$. The materials were mechanically tested in tension at temperatures and strain rates varying in the ranges of $-50^{\circ} \mathrm{C} \ldots 80^{\circ} \mathrm{C}$ and $10^{-3} \mathrm{~s}^{-1} \ldots 1250 \mathrm{~s}^{-1}$, respectively. Due to the temperature dependence of $\gamma_{S F E}$, also the mechanical behavior of TWIP steels reveals clear temperature dependence, determined by the prevailing deformation mechanism, i.e., dislocation slip, deformation twinning, or $\varepsilon$-martensite transformation. In addition to the 'ordinary' strain rate sensitivity, an increase in temperature due to adiabatic deformation heating contributes to the stacking fault energy (SFE) at high strain rates, shifting $\gamma_{S F E}$ towards the dislocation slip regime and this way strongly affecting also the mechanical behavior. At stacking fault energies close to the transition between twinning and $\varepsilon$-martensite transformation, lowering the temperature can ultimately result in entering the $\varepsilon$-martensite transformation regime that may bring about further ductility.
\end{abstract}

Keywords: High manganese TWIP steels, mechanical behavior, stacking fault energy.

\section{INTRODUCTION}

The extraordinary combination of ductility and strength of high manganese TWIP steels is commonly explained by the continuous progression of mechanical twinning $\gamma \rightarrow \gamma_{T}^{\prime}$ during deformation of the material. Mechanical twins, forming during straining, act as sub-boundary-like obstacles to dislocation motion, bringing about the gradual strain hardening typical of TWIP steels by a Hall-Petch type of strengthening.

The most fundamental nucleation parameter, which determines whether twinning, martensite transformation, or dislocation glide will occur, is the stacking fault energy $\gamma_{S F E}$. The typical $\gamma_{S F E}$ range for the occurrence of twinning presented in the literature is $18 \leq \gamma_{S F E} \leq 45 \mathrm{~mJ} / \mathrm{m}^{2}$ [1-2]. With further decreasing stacking fault energies and at the same time a negative value of the molar Gibbs energy of the martensitic reaction $\gamma_{f c c} \rightarrow \alpha_{b c c}^{\prime M s}$, first $\varepsilon$-martensite formation $\gamma_{f c c} \rightarrow \varepsilon_{h c p}^{M s}$, and for even lower SFE's $\alpha^{\prime}$-martensite formation $\gamma_{f c c} \rightarrow\left(\varepsilon_{h c p}^{M s}\right) \rightarrow \alpha_{b c c}^{\prime M s}$ become the dominant deformation/hardening mechanisms. When exceeding stacking fault energies of approximately $45 \mathrm{~mJ} / \mathrm{m}^{2}$, plasticity is controlled solely by dislocation glide.

To fully exploit twinning and/or phase transformation mechanisms in austenitic steels, the magnitude of $\gamma_{S F E}$ can be adjusted by appropriate chemical alloying. In the present study, three experimental fully austenitic high manganese TWIP steel grades were produced. The SFE of the three materials was calculated based on the thermodynamic modeling approach originally proposed by OLSON and COHEN [ $\underline{3}$, where the ideal stacking fault energy is expressed as

$$
\gamma_{S F E}=2 \rho \Delta G^{\gamma \rightarrow \varepsilon}+2 \sigma
$$

with $\rho$ the molar surface density along $\{111\}$ planes, $\Delta G^{\gamma \rightarrow \varepsilon}$ the molar Gibbs energy of the $\gamma \rightarrow \varepsilon$ phase transformation, and $\sigma$ the interfacial energy per unit area of phase boundary. 
In addition to the chemical composition, the twinning propensity is determined by external factors, i.e., the temperature, the applied strain rate, the loading conditions, etc. In most metals the contribution of twinning to the deformation increases as the temperature is lowered, which can be explained by the fact that the critical twinning stress $\tau_{C}$ in most materials increases less rapidly with decreasing temperature than the yield or flow stress for deformation by slip. Although for fcc metals the yield stress shows rather weak sensitivity to temperature, the flow stress may ultimately reach the twinning stress by work hardening, and so the slip-to-twinning transition upon lowering the temperature is governed, at least partly, by the strong temperature dependence of the work hardening rate [4]. However, also the stacking fault energy $\gamma_{\mathrm{SFE}}$, which in turn affects the twinning stress $\tau_{C}[\underline{5}]$, is altered when changing the temperature, and may therefore result in a change in the governing deformation mechanism. An increase in strain rate usually results in increased twinning propensity [4]. However, under high strain rate deformation a distinct rise in temperature due to adiabatic deformation heating can raise the SFE either towards, or off the optimum value for twinning, depending on the initial SFE value.

\section{EXPERIMENTAL PROCEDURE}

Three fully austenitic high manganese TWIP steel grades were prepared. Bars of $60 * 90 * 400 \mathrm{~mm}$ were cast in 0.2 bar argon atmosphere after induction melting in a vacuum furnace. The bars were reheated at $1200{ }^{\circ} \mathrm{C}$ and hot rolled to sheets of $2 \mathrm{~mm}$ in thickness. The finish rolling temperature was $900{ }^{\circ} \mathrm{C}$ and the 'coiling' temperature $600{ }^{\circ} \mathrm{C}$. The chemical compositions of the studied TWIP steels together with the calculated $\gamma_{S F E}$ values for the Fe-Mn-Al-Si-C systems are presented in Table 1. The stacking fault energy of the three studied materials as a function of temperature is shown in Figure 1a.

Table 1: Chemical compositions of the tested TWIP steels as obtained from Baird Dv-6 optical emission spectrometer measurements.

\begin{tabular}{c|c|c|c|c|c|c|c|c}
\hline Material & Mn [\%] & Al [\%] & Si [\%] & $\begin{array}{c}\mathbf{C} \\
{[\%]}\end{array}$ & $\mathbf{C r}+\mathbf{M o}[\mathbf{\%}]$ & $\begin{array}{c}\mathbf{N b} \\
{[\mathbf{\%}]}\end{array}$ & $\begin{array}{c}\mathbf{F e} \\
{[\mathbf{\%}]}\end{array}$ & $\begin{array}{c}\gamma_{\mathbf{S F E}} \\
{\left[\mathbf{m J} / \mathbf{m}^{2}\right]}\end{array}$ \\
\hline TWIP 1 & 28 & 1.6 & 0.28 & 0.08 & $<0.01$ & $<0.001$ & Bal. & 27 \\
\hline TWIP 2 & 25 & 1.6 & 0.24 & 0.08 & $<0.01$ & 0.05 & Bal. & 20.5 \\
\hline TWIP 3 & 27 & 4.1 & 0.52 & 0.08 & $<0.01$ & 0.05 & Bal. & 42 \\
\hline
\end{tabular}

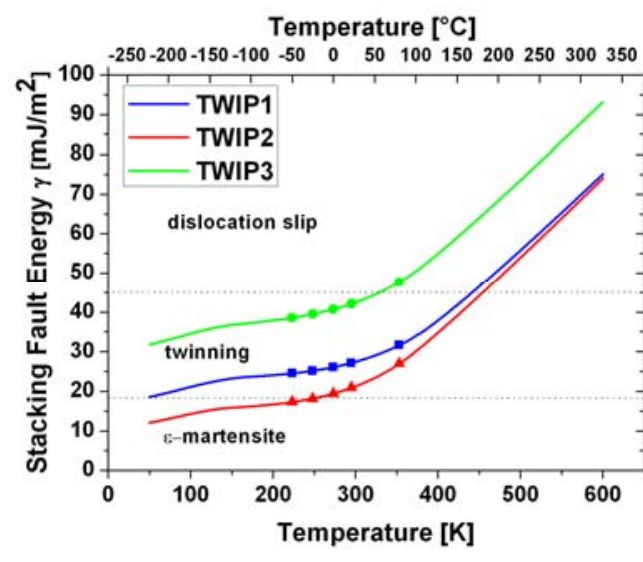

(a)



(b)

Figure 1: (a) The stacking fault energies $\gamma_{\mathrm{SFE}}$ of the TWIP steel alloys 1-3 as a function of temperature. The temperatures at which mechanical test were conducted are indicated by markers. (b) Strain hardening rates $\theta$ $=\mathrm{d} \sigma / \mathrm{d} \varepsilon$ of the TWIP $1-3$ steel grades at strain rate $10^{-3} \mathrm{~s}^{-1}, \mathrm{~T}=22^{\circ} \mathrm{C}$.

Dog-bone shaped tensile test specimens were prepared from the hot rolled steel sheets using a milling cutter. The specimens' tensile axis was parallel to the rolling direction; the gage length was $6 \mathrm{~mm}$, the width ca. $3.5 \mathrm{~mm}$, and the transition zone fillet radius $1 \mathrm{~mm}$.

The materials were studied with tensile tests at strain rates ranging from $10^{-3} \mathrm{~s}^{-1}$ to $1250 \mathrm{~s}^{-1}$ and temperatures varying between $-50{ }^{\circ} \mathrm{C} \leq \mathrm{T} \leq 80^{\circ} \mathrm{C}$. The low strain rate experiments were performed using a servohydraulic materials testing machine while for the high strain rate tests the Hopkinson split bar technique was utilized in a direct tensile setup. The temperature during the tests was varied using specially designed 
temperature control systems. Both the test setup and specimen geometry are described in more detail for instance in Ref. [6].

\section{RESULTS AND DISCUSSION}

At room temperature the strain hardening rate $\theta=d \sigma / d \varepsilon$ is initially stronger for the material with the highest stacking fault energy, i.e., TWIP 3, but at higher strains the case appears to be clearly the opposite, as can be seen in Figure 1b. This indicates that there are some differences in the strain induced hardening mechanisms between the steels, especially between TWIP 2 and 3. The SFE of TWIP 3 is clearly higher than that of TWIP 2 (42 as opposed to $20.5 \mathrm{~mJ} / \mathrm{m}^{2}$ ), and in fact the high SFE value $\gamma_{S F E}=42 \mathrm{~mJ} / \mathrm{m}^{2}$ might already indicate a change in the governing deformation mechanism from twinning to dislocation slip.
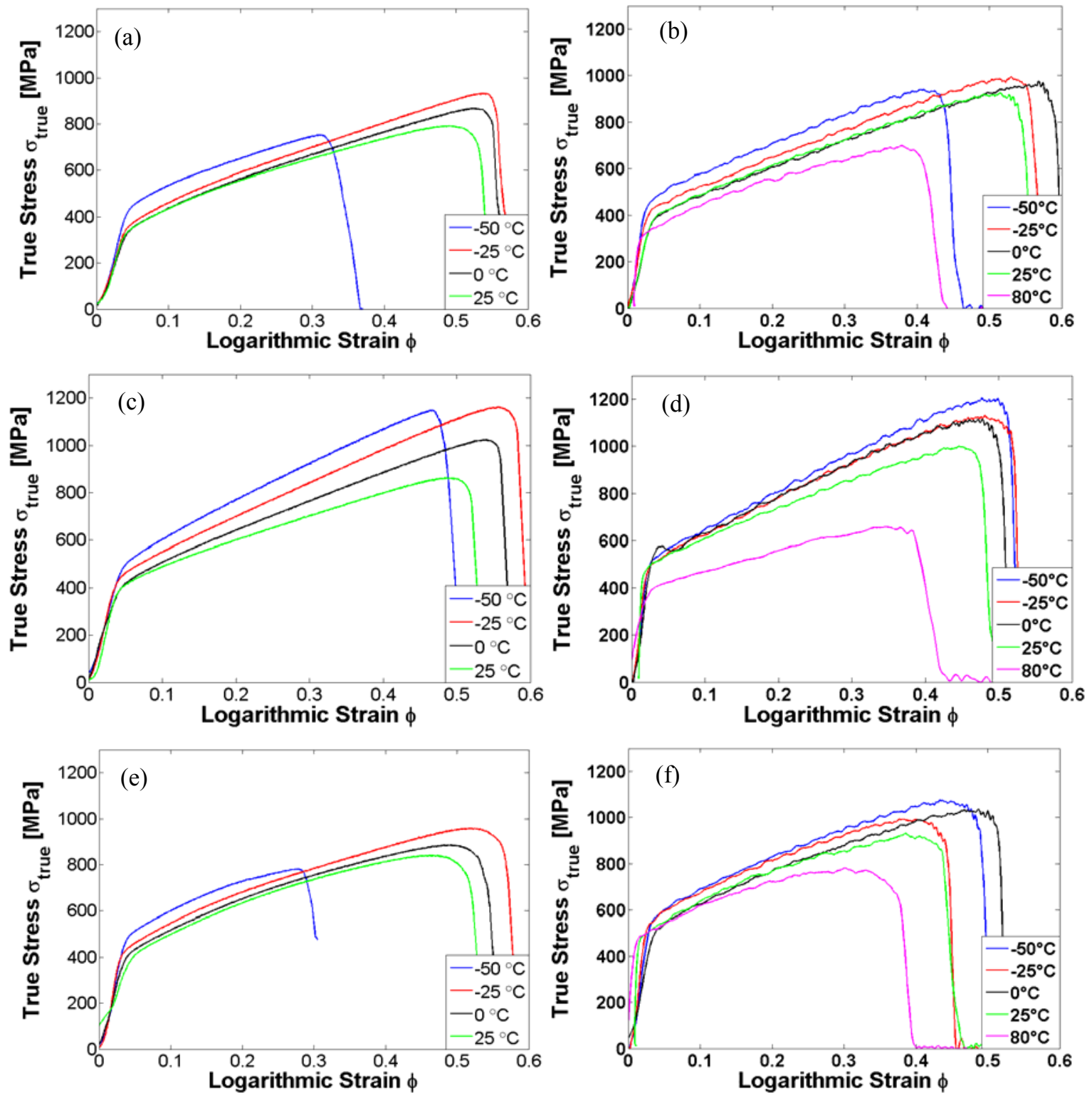

Figure 2: True stress vs. logarithmic strain curves of TWIP 1 at different temperatures at the strain rates of $10^{-3} \mathrm{~s}^{-1}(\mathrm{a})$, and $1250 \mathrm{~s}^{-1}(\mathrm{~b})$, TWIP 2 at $10^{-3} \mathrm{~s}^{-1}(\mathrm{c})$, and $1250 \mathrm{~s}^{-1}(\mathrm{~d})$, and TWIP 3 at $10^{-3} \mathrm{~s}^{-1}(\mathrm{e})$, and $1250 \mathrm{~s}-1$ (f).

The true stress vs. logarithmic strain curves of the three experimental TWIP steels are shown in Figure 2, and their yield strength (YS) and ultimate tensile strength (UTS) values at strain rates $10^{-3} \mathrm{~s}^{-1}$ and $1250 \mathrm{~s}^{-1}$ as plotted against the temperature in Figures $3 \mathrm{a}$ and $3 \mathrm{~b}$. The yield strength was determined from the 
engineering stress-strain curves as the intersection point of the lines fitted to the elastic and plastic regions (between about 2 and $10 \%$ of plastic strain) of the curve, while the UTS value was determined as the stress maximum in the engineering stress-strain curve. The yield strength and UTS of the three TWIP steels increase only moderately with decreasing temperature, which is in agreement with the observations on TWIP steels reported by other research groups [1] and considered a characteristic behavior for pure fcc metals.
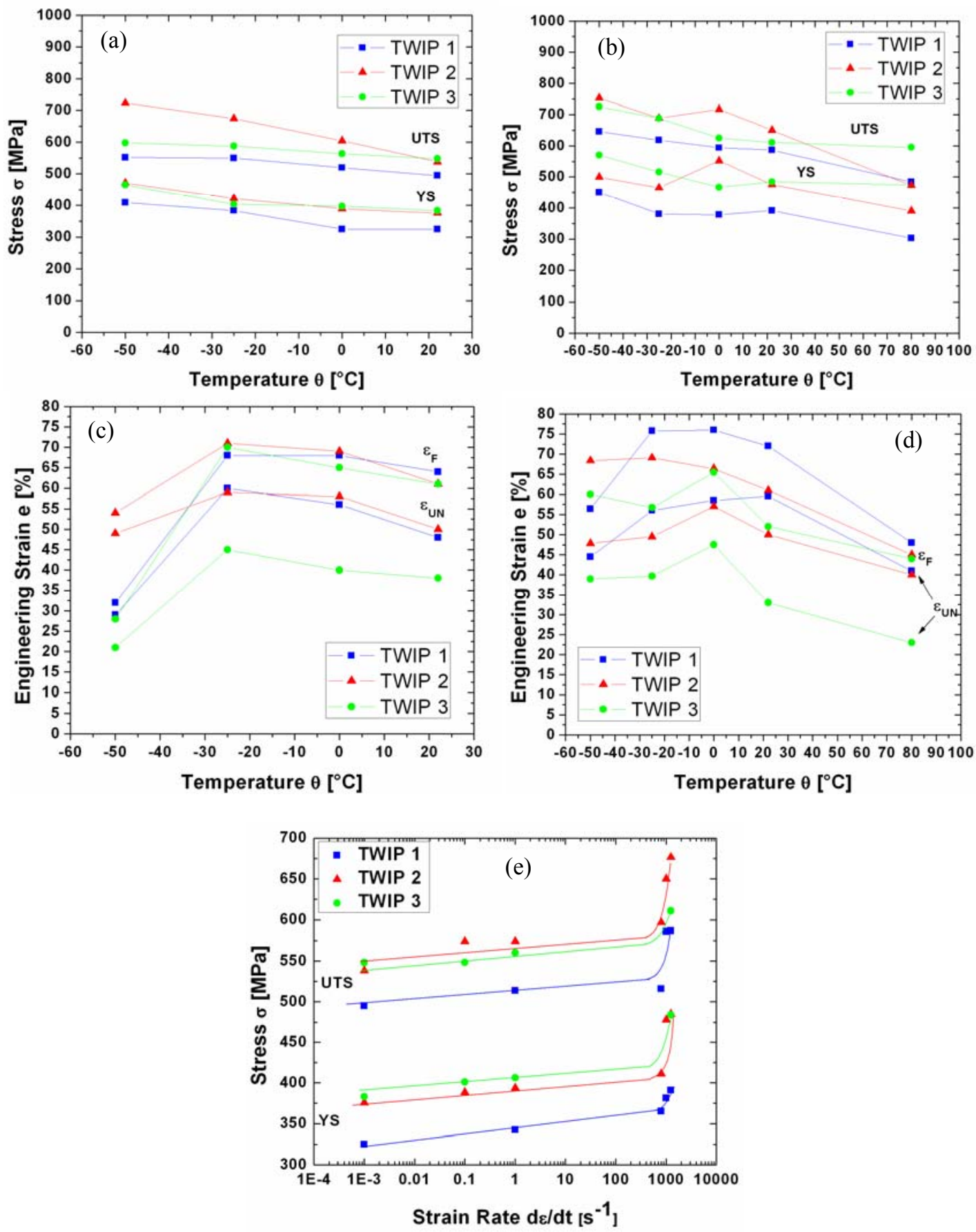

Figure 3: YS and UTS of the TWIP steels as a function of the (initial) deformation temperature at strain rates (a) $10^{-3} \mathrm{~s}^{-1}$ and (b) $1250 \mathrm{~s}^{-1}$, the corresponding uniform elongations $\mathrm{e}_{\mathrm{un}}$ and total elongations $\mathrm{e}_{\mathrm{f}}$ at strain rates (c) $10^{-3} \mathrm{~s}^{-1}$ and (d) $1250 \mathrm{~s}^{-1}$, as well as YS and UTS of as a function of the strain rate for all three materials (e).

TWIP 1 shows the lowest strength values over the whole covered temperature range, as well as over the studied strain rate range, as can be seen from Figure $3 \mathrm{e}$. This is probably due to the absence of niobium in TWIP 1, which is known as a precipitation hardener. At low strain rates (Figure 3a), the temperature dependence of the yield strength of all three materials is almost identical. However, the ultimate tensile 
strength of TWIP 2 increases clearly faster with decreasing temperature than the UTS of the two other materials, revealing the strongest temperature sensitivity. At high strain rates such a clear correlation between strength and temperature for the three materials is not so evident, as Figure $3 \mathrm{~b}$ shows.

In Figures $3 \mathrm{c}$ and $3 \mathrm{~d}$, the uniform elongation $e_{\mathrm{un}}$ and the total elongation $e_{\mathrm{f}}$ of the studied materials are plotted as a function of the initial test temperature for the strain rates $10^{-3} \mathrm{~s}^{-1}$ and $1250 \mathrm{~s}^{-1}$, respectively. In general, both the uniform and total elongations show maximum values at a certain temperature, below and above which the values decrease when shifting the temperature off the point of maximum elongation. This behavior, typical of high manganese TWIP steels, is usually explained as follows: the amount of deformation twins formed during plastic deformation increases upon lowering the temperature since the stacking fault energy $\gamma_{\mathrm{fcc}}$ is lowered into the region, where twinning as a deformation mechanism becomes energetically favored over dislocation motion. At the temperature of maximum elongation, twinning proceeds most gradually during the deformation progress, thus fully exploiting the TWIP effect. At even lower temperatures, most of the twinning occurs in the early stages of deformation, leading to a loss of the TWIP effect and hence to decreasing elongation values with decreasing temperature.

At low strain rates, all three studied TWIP steels show maximum elongations some-where between $30{ }^{\circ} \mathrm{C}$ and $0{ }^{\circ} \mathrm{C}$, as can be seen from Figure $3 \mathrm{c}$; more data points in that temperature interval would be needed for the exact determination of the maximum values. At high strain rates, TWIP 1 shows maximum elongations at $-25{ }^{\circ} \mathrm{C} \leq \mathrm{T} \leq \mathrm{RT}$, TWIP 2 at $-50{ }^{\circ} \mathrm{C} \leq \mathrm{T} \leq 0{ }^{\circ} \mathrm{C}$, and TWIP 3 at $-25{ }^{\circ} \mathrm{C} \leq \mathrm{T} \leq 0{ }^{\circ} \mathrm{C}$. TWIP 3 shows clearly the lowest uniform elongations at all strain rates and temperatures, and by tendency also the lowest total elongation values. In the temperature range $-25^{\circ} \mathrm{C} \leq \mathrm{T} \leq \mathrm{RT}$, TWIP 1 and TWIP 2 reveal roughly the same levels of $e_{u n}$ and $e_{f}$ at low strain rates, but at lower temperatures the ductility of TWIP 1 decreases drastically, while the decrease in the ductility of TWIP 2 is only moderate. The total elongation values of TWIP 3 are more or less comparable to those of TWIP 1 at all temperatures.

The reason why TWIP 2 retains more of its ductility at $-50{ }^{\circ} \mathrm{C}$ than TWIP 1 and TWIP 3 may be explained by its lower SFE. By decreasing the temperature to $-50{ }^{\circ} \mathrm{C}$, the stacking fault energy of TWIP 2 is lowered from its original value at room temperature, $\gamma_{S F E}=20.5$, to $\gamma_{S F E}=17.9 \mathrm{~mJ} / \mathrm{m}^{2}$. According to ALLAIN et al. [2] , the formation of $\varepsilon$-martensite sets in at stacking fault energies below $18 \mathrm{~mJ} / \mathrm{m}^{2}$. At lower temperatures mechanical martensite transformation might therefore partly compensate for the reduced mechanical twinning rate at high levels of strain. However, no XRD of TEM measurements were conducted on the specimens deformed at low temperatures to confirm this.

In TWIP steels, two separate effects influencing the mechanical behavior come into play at high strain rates: adiabatic heating of the specimen on the one hand, especially at high strains, and extensive twin formation, which has been observed by several re-searchers in materials under high strain rate deformation $[1,7]$, on the other hand. With these two effects, some of the dynamic material behavior results observed in the present study can be explained. Under high strain rate deformation at $80{ }^{\circ} \mathrm{C}$, TWIP 3 ex-hibits the lowest ductility, and also the strain hardening behavior revealed by the stress strain curve in Figure $2 \mathrm{f}$ indicates nonoptimal exploitation of the TWIP effect. Indeed, the SFE value of TWIP 3 at $80{ }^{\circ} \mathrm{C}$ shown in Figure 1a has clearly shifted into the dislocation slip regime. TWIP 1 exhibits both the highest uniform and total elongation values, which also remain the highest of the three materials with decreasing temperatures down to $-25{ }^{\circ} \mathrm{C}$. However, towards even lower temperatures, the same behavior as in the low strain rate tests is observed, i.e., the ductility of TWIP 2 remains at a comparably higher level than that of the other two materials. Unlike at low strain rates, however, no drama-tic decrease in the elongation values of TWIP 3 is observed either, and for all three materials the total elongations at $-50{ }^{\circ} \mathrm{C}$ obtained at high strain rates exceed the total elongations of the same materials deformed at low strain rates. This is obviously a result of the higher twinning propensity at high strain rates on the one hand, but even more a result of adiabatic heating, increasing the actual specimen temperature from below the maximum elongation temperature towards the optimum temperature. With increasing initial test temperatures, however, the case becomes the opposite, and the elongations observed under low strain rate deformation are larger than those observed at high strain rates. Again the behavior can be explained by adiabatic heating, this time shifting the internal specimen temperature off the maximum elongation temperature. Calculating the adiabatic temperature rise according to the equation:

$$
\Delta T=\frac{\Delta Q}{\rho C_{P}}=\frac{\beta}{\rho C_{P}} \int_{\varepsilon_{1}}^{\varepsilon_{2}} \sigma d \varepsilon
$$

where the fraction of mechanical energy that is converted to heat energy $\Delta Q$ is assumed to be $\beta=$ 0.9 , the typical specific heat capacity of steel is taken as $C_{P}=0.46 \mathrm{~kJ} / \mathrm{kg} \mathrm{K}$, the density as $\rho=7.8 \mathrm{~g} / \mathrm{cm}^{3}$, and using $E_{\text {mech }}=38 \mathrm{~J} / \mathrm{mm}^{3}$ as the total mechanical energy generated under actual test conditions by integrating the area under the $\sigma-\varepsilon$ curve, a temperature increase of $95{ }^{\circ} \mathrm{C}$ is obtained at the end of the test. Depending on 
the slope $\partial \gamma_{S F E} / \partial T$ of the $\gamma_{S F E}$ vs. $T$ curve in Figure 1a, the increase in the stacking fault energy caused by the total temperature increase can be up to $25 \mathrm{~mJ} / \mathrm{m}^{2}$, what explains also the substantial drop in the elongation values in Figure $3 \mathrm{~d}$ for temperatures ca. $T>20^{\circ} \mathrm{C}$, coinciding with the change in the slope of the $\gamma_{S F E}$ vs. $T$ curve.

Overall, TWIP 2, which had the lowest SFE, revealed the most stable mechanical performance over the entire temperature and strain rate range and showed the most beneficial strength and ductility combination of all three TWIP steels. TWIP 1 revealed the lowest strength values under any condition, while TWIP 3 in general showed the lowest elongation values. TWIP 2 showed also superior UTS/YS ratios when compared to the other two materials.

Since the combined effects of temperature, strain rate, and stacking fault energy on the twinning and other hardening mechanisms of the studied alloys seem to be very complex, more research is still needed to form a complete picture of the mechanical behavior of TWIP steels. For example, precise determination of the stacking fault energies of multi-element alloys is still very difficult both theoretically and experimentally, which leaves too much room for guesswork in the interpretation of the experimental results of these materials.

\section{CONCLUSIONS}

Three fully austenitic experimental high manganese TWIP steel grades, differing slightly in their contents of $\mathrm{Mn}, \mathrm{Al}, \mathrm{Si}$, and $\mathrm{Nb}$, were produced based on thermodynamic stacking fault energy calculations. The stacking fault energies of the steels varied between about 20.5 and $42 \mathrm{~mJ} / \mathrm{m}^{2}$ at room temperature, causing differences in their mechanical behavior, especially when the testing conditions, i.e., temperature and/or strain rate were varied.

Of the three TWIP steels tested in tension, TWIP 1, which does not contain niobium, showed clearly the lowest strength values at all testing conditions. Additions of $\mathrm{Nb}$ seemed to increase the strength of the TWIP steels without compromising their ductility.

The strain hardening behavior of TWIP 2 and TWIP 3, which due to their different contents of aluminum and silicon have the largest difference in their stacking fault energies, showed some clear differences. TWIP 3 initially strain hardened stronger, but TWIP 2 maintained higher strain hardening potential up to high strain levels.

The strength values of the studied TWIP steels increased steadily with decreasing temperature. Both uniform and total elongations showed maximum values in the temperature region of $-50{ }^{\circ} \mathrm{C}<\mathrm{T}<0{ }^{\circ} \mathrm{C}$, where mechanical twinning has the strongest effect on the mechanical properties of austenitic steels.

At high strain rates combined with high initial testing temperatures, all TWIP steels showed a clear reduction in their elongation values, which was attributed to the increase in the stacking fault energy due to the higher initial test temperature in combination with adiabatic deformation heating, causing dislocation slip to take over from twinning as the hardening rate controlling deformation mechanism and thus resulting in a reduced TWIP effect.

The strength-ductility combination of TWIP 3 was overall the poorest of the studied steels, its SFE being too close to the deformation slip regime to truly benefit from twinning. TWIP 2 , which has the lowest stacking fault energy $\gamma_{S F E}$ of the studied steels, revealed the most beneficial elongation-strength combination persisting down to low temperatures, probably because of the mechanical martensite transformation coming into play at low temperatures.

\section{REFERENCES}

[1] GRÄSSEL, O., KRÜGER, L., FROMMEYER, G., MEYER, L.W., "High strength Fe-Mn-(Al, Si) TRIP/TWIP steels development - properties - application", International Journal of Plasticity, v. 16, n. 10-11, pp. $1391-1409,2000$.

[2] ALLAIN A., CHATEAU J.-P., BOUAZIZ O., MIGOT S., GUELTON N., "Correlations between the calculated stacking fault energy and the plasticity mechanisms in Fe-Mn-C alloys", Materials Science and Engineering A, v. 387-389, pp. 158-162, December 2004.

[3] OLSON, G.B., COHEN, M., "General mechanism of martensitic nucleation .1: General concepts and FCC-]HCP transformation”, Metallurgical Transactions, v. 7, n. 12, pp. 1897-1904, 1976.

[4] CHRISTIAN, J.W., MAHAJAN, S., "Deformation Twinning", Progress in Materials Science, v. 39, n. 12, pp. 1-157, 1995. 
[5] VENABLES, J.A., "Deformation twinning in face-centred cubic metals", Philosophical Magazine, v. 6, pp. 379, 1961.

[6] CURTZE, S., KUOKKALA, V.-T., HOKKA, M., PEURA, P., "Effects of composition, temperature and strain rate on the mechanical behavior of high-alloyed manganese steels", In: Conference Proceedings New Developments in Metallurgy and Applications of High Strength Steels, Buenos Aires, Argentina, May 2008.

[7] HOKKA, M., KUOKKALA, V.-T. , CURTZE, S., VUORISTO, T., APOSTOL, M., "Characterization of strain rate and temperature dependent mechanical behavior of TWIP steels", Proceedings Dymat 2006, Dijon, France, 2006. 